\title{
Preparation and Application of an Low-Aluminium Tap Water Flocculant
}

\author{
Defang Zeng, Jun Liu \\ Hubei Key Lab of Mineral Resource Processing and Environment, School of Resource and Environmental Engineering, \\ Wuhan University of Technology, Wuhan, China \\ Email:854339507@qq.com
}

Received April 27, 2013; revised May 25, 2013; accepted June 10, 2013

Copyright (C) 2013 Defang Zeng, Jun Liu. This is an open access article distributed under the Creative Commons Attribution License, which permits unrestricted use, distribution, and reproduction in any medium, provided the original work is properly cited.

\begin{abstract}
A kind of environmental friendly novel composite flocculants which are used to treat raw water is prepared. It is made with chitosan (CS), iron modified polyaluminium chloride (CF-PAC) and modified montmorillonite on the principle of "the combination of organic and inorganic". Under the optimum best compound formula and flocculation process, the turbidity of the waste water reduced by $0.62 \%$, the chemical cost decreased by $12.43 \%$ and the content of aluminium ions dropped by $70.65 \%$. There is an excellent characteristic and higher efficiency on the composite flocculant which can adsorb the organic matter in the water and chelate the heavy metal ions in the water.
\end{abstract}

Keywords: Composite Flocculant; Chitosan; Tap Water Treatment; Aluminium Ion

\section{Introduction}

At present, more and more people begin to pay close attention to the safety of drinking water. The traditional flocculants [1], such as aluminium salt and polyacrylamide [2], are widely used in water treatment, but it will leave large amounts of high concentration of metal ions and produce a mass of sludge with heavy metal. It is seriously harmful to human health if the treated water contain aluminium ion getting into human body with the tapater $[3,4]$. Moreover, the traditional treatment process is very complicate and it will bring the seriously secondary pollution inevitably. Therefore, it is necessary to develop an environmental friendly flocculant without aluminium or low aluminium which could be better used in water treatment. With the development of the biodegradable natural polymers flocculants research, the rich raw material sources with the properties of low price, non-toxic, biodegradable and no secondary pollution have attracted attention. There are many kinds of natural polymer flocculants [5-8] such as starch, chitosan, lignin, protein, algae, etc.

Molecular structure of chitosan is linear type [9]. The typical cationic chitosan flocculants were related to the protonation of a large amount of amino group in acid solutions [10]. There is a wide application prospect on montmorillonite in the field of water treatment because of its rich resources in our country and its excellent ad- sorptive capacity of the modified montmorillonite [11]. During the flocculant experiment, according to the synergy of "organic-inorganic compound" to find the best formula and the best reagent dosing quantity, the chitosan has showed its bridging and electro-dissociation reaction. Chitosan used for suspension in the treatment of industrial wastewater has become a research hotspot [12], but used as a flocculant in water processing of metal ions and turbidity residue in water was not enough. Therefore, the article analyses and studies on the issue of chitosan.

\section{Experiment}

\subsection{Chemicals}

Chitosan (made in lab), CF-PAC and PAC PFS (Nanjing Chemical Industry Corporation, Nanjing, P.R. China). PFS (Hefei Yimin Chemical Industry, Hefei, P.R. China). The cationic polyacrylamide $\left(\mathrm{PAM}^{+}\right.$, molecular weight was 1.5 million, supplied by Japan's Mitsubishi Company). The Natural montmorillonite (the mass fraction was more than $70 \mathrm{wt} \%$, the fineness under $0.043 \mu \mathrm{m}$ and specific surface area was $260 \mathrm{~m}^{2} \cdot \mathrm{g}^{-1}$, XiangYang miners factory in Hubei province, Hubei, P.R. China). Glacial acetic acid (supplied by chemical plant of Hubei University, Hubei, P.R. China). Aluminium single element standard solution $\left(100 \mathrm{mg} \cdot \mathrm{L}^{-1}\right.$, National Standard Substances Center). Sodium hydroxide, sodium phosphate 
and other chemicals are analysis pure.

\subsection{Raw Water}

The experiment water was obtained from The Yangtze River in the section of Wuhan in China in August, the initial value was determined after the raw water samples was obtained, the initial turbidity is $71.8 \mathrm{NTU}$, temperature of the water was $21^{\circ} \mathrm{C}$ to $23^{\circ} \mathrm{C}$, pH was 7.3 to 7.6 .

\subsection{Preparation of the CS Working Liquid}

First, amount of chitosan was dissolved directly in $2 \%$ acetic acid solution with the volume $500 \mathrm{ml}$ and then water-bath heated to $80^{\circ} \mathrm{C}$ under ordinary conditions of pressure, then pour $2.5 \%$ hydrogen peroxide into the liquid about $2.5 \mathrm{~h}$ later, pour into $40 \% \mathrm{NaOH}$ solution and string for an hour. Then the chloroacetic acid solution was poured in drip by drip slowly and put the solution under temperature of $50^{\circ} \mathrm{C}$ for 2 hours. The pale yellow transparent sols would appear. After the reaction was finished, the kettle is naturally cooled to room temperature, adjusts the solution $\mathrm{pH}$ value until neutral with glacial acetic acid, add some distilled water, it was super centrifuged and gel filtration after stirring fully, then take the supernatant. Adding 85\% ethanol to supernatant and rapidly mixing precipitation, make the suction filter after precipitation completely, drying residue about 5 hours after remove surface moisture, it would changed into the powdered chitosan. The kind of powdered chitosan made in this condition, its molecular weight was $1 \times 10^{4}$ to $2 \times$ $10^{4}$, intrinsic viscosity was $13.75 \mathrm{~mL} \cdot \mathrm{g}^{-1}$, the deacetylation degree was $85 \%$.

Take $0.25 \mathrm{~g}$ powdered chitosan with electronic balance, dissolve it into $1 \%$ acetic acid solution, then pour the liquid into a flask with the volume $500 \mathrm{~mL}$. At last, add into the $1 \%$ acetic acid solution to the scale line.

\subsection{Preparation of the Modified Montmorillonite Working Liquid}

$3 \mathrm{wt} \%$ water slurry suspension was made with montmorillonite which was dissolved in distilled water, add sodium phosphate (dispersant) and magnesium oxide (suspension agent) whose quality was $5 \%$ of montmorillonite and $0.5 \%$ of montmorillonite, and then put it in the $4000 \mathrm{r} \cdot \mathrm{min}^{-1}$ high-speed dispersion machine for 2 hours until the suspending liquid was uniform. That is the montmorillonite liquid.

In the condition of normal temperature, normal atmospheric pressure and continue stirring, drop the aluminium cross linking agent into montmorillonite suspendsion in a certain proportion. And then on the speed of $200 \mathrm{r} \cdot \mathrm{min}^{-1}$ mixer mixing 2 hours, after placed one day, the aluminium cross-linked montmorillonite sus- pendsion was made up. Dry the aluminium cross-linked montmorillonite suspension and grind to powder, add it into waster to make up 3\% (mass ratio) suspension for use. To improve experimental precision, the $3 \%$ suspension above was diluted 10 times with distilled water in volumetric flask, so the $0.3 \%$ of the liquid was made up.

\subsection{Preparation of the CF-PAC, PFS and PAM ${ }^{+}$ Working Liquid}

Take $0.25 \mathrm{~g}$ powdered CF-PAC with electronic balance, Dissolve it with distilled water and dilute with water to $500 \mathrm{~mL}$. PFS, $\mathrm{PAM}^{+}$working liquid were prepared with the same method.

\subsection{Experimental Methods}

Shake well and take $200 \mathrm{~mL}$ water sample to $250 \mathrm{~mL}$ beaker, put stir bar into the beaker, added the amount of flocculant according to the principle of "organic after inorganic compounds", continue stirring with the constant temperature magnetic stirrer (HJ-3 type). Adjusting stirring speed, the stirring speed was $250 \mathrm{r} \cdot \mathrm{min}^{-1}$ for 3 min at beginning, then the speed changed to $50 \mathrm{r} \cdot \mathrm{min}^{-1}$ for $8 \mathrm{~min}$, placed for $15 \mathrm{~min}$, then take the supernatant fluid to determine the turbidity and aluminium ion. The turbidity was determined by WGZ-100 type photoelectric turbidity measurement and aluminium ion content was determined by the FLAN-6000 inductively coupled plasma mass spectrometry single element standard solution. The experimental process was shown in Figure 1:

\section{Results and Discussion}

\subsection{The Composite Flocculation Effect of CS with Modified Montmorillonite, CF-PAC and PAC}

With prices of PAC flocculant in Hubei Gedian as reference, we design the compound formula of flocculants below the PAC price, which the PAC working liquid is 14.3 Yuan $\mathrm{kg}^{-1}$ and the cost of 1 ton water treatment is 0.286 Yuan. The price as the major factor, taking CSModified montmorillonite composite flocculants as an

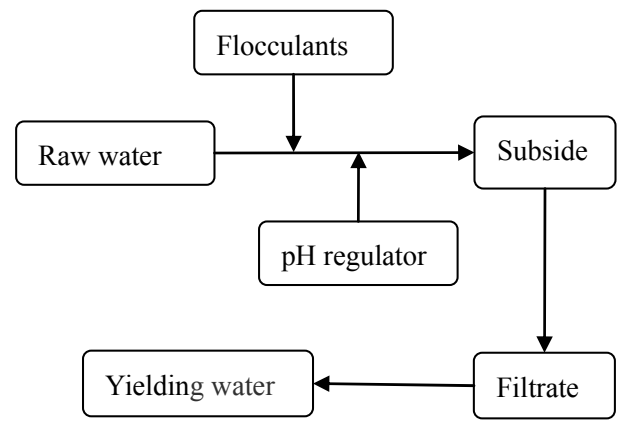

Figure 1. Experimental process. 
example, determine disperse point during the limited cost after the dosage of CS and the sum certain in money. The preparation and component content of other composite flocculants in this same way.

According to the above design principles of flocculants to determined the advantage formulas and retrofit it. Modified montmorillonite is combined with CS and $\mathrm{PAM}^{+}$respectively, to analyze the flocculation effects, as shown in Figure 2 and Figure 3 below. Traditional flocculation effect is shown in Figure 2 CS-Modified montmorillonite has good flocculation effect, flocculation efficiency between $72 \%$ and $92 \%$, CS shows obvious advantages. The results of the flocculation effects show the CS-Modified montmorillonite is roughly stable, which has no better advantages compare with the traditional in Figure 2. $\mathrm{PAM}^{+}$-Modified montmorillonite overall flocculation effects is good and stable, the removal rate of SS is around $92 \%$ float, which the effect is better with the dosage of $\mathrm{PAM}^{+}$is $0.625 \mathrm{ppm}$ in Figure 3.

According to Figure 4 CS-CF-PAC composite flocculation effect is very ideal, and flocculation process is relatively stable, its peak flocculation effect can reach 97.23\%. Figure $5 \mathrm{PAM}^{+}-\mathrm{CF}-\mathrm{PAC}$ composite flocculation effect is more stable than the CS-CF-PAC, which floating flocculation efficiency around 95\%, the same level of the best flocculation effect as the CS-CF-PAC.

As shown in Figure 6, CS-PFS compound flocculation

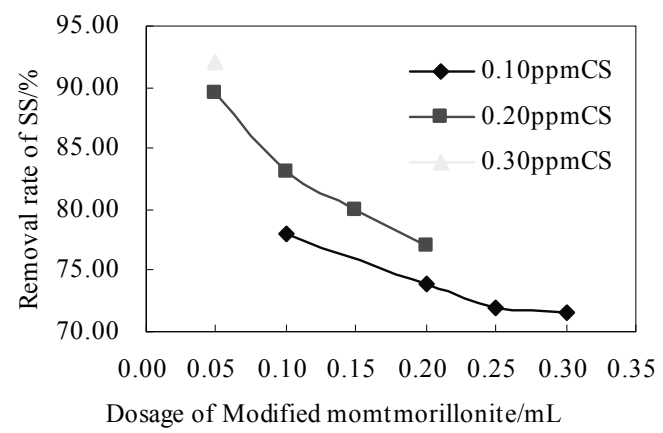

Figure 2. Flocculation effect of CS-Modified montmorillonite.

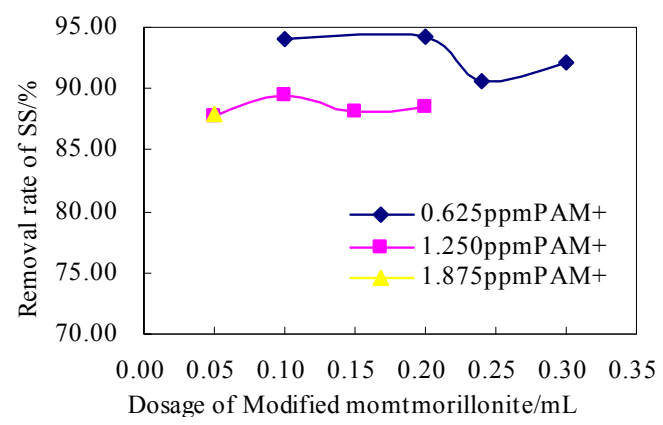

Figure 3. Flocculation effect of $\mathbf{P A M}^{+}$-Modified montmorillonite.

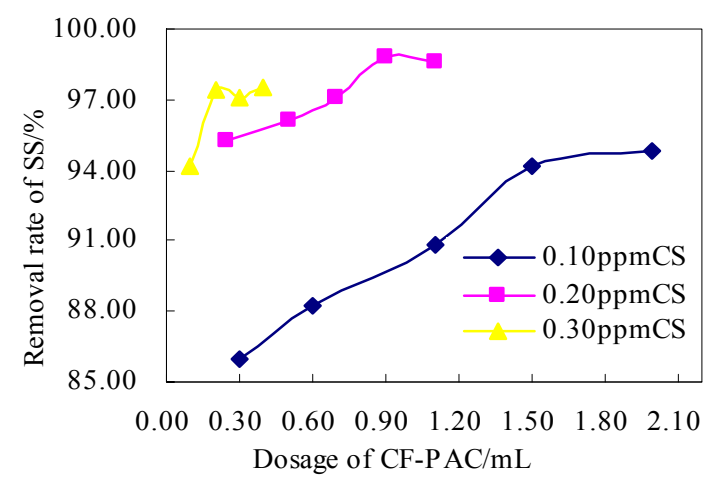

Figure 4. Flocculation effect of CS-CF-PAC combination.

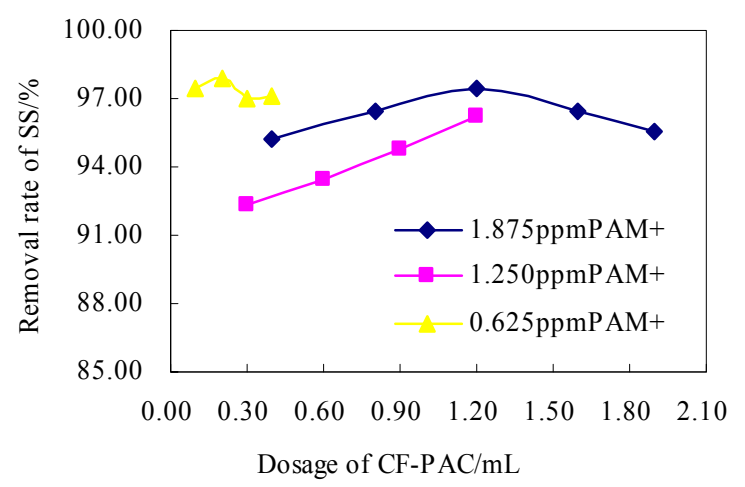

Figure 5. Flocculation effect of $\mathbf{P A M}^{+}$-CF-PAC combination.

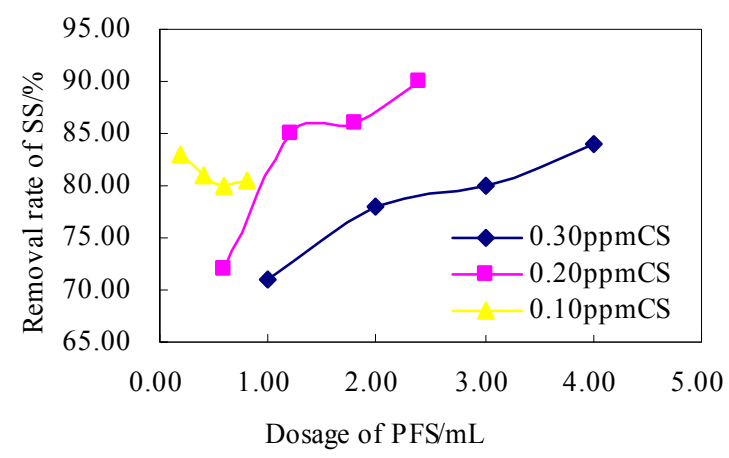

Figure 6. Flocculation effect of CS-PFS combination.

has no better advantages and unstable, the highest removal rate about $90 \%$ without advantage, the flocculateing effects were similar. The $\mathrm{PAM}^{+}$-PFS compound flocculation effect in Figure 7, and its flocculation effect increases with the growth in the flocculant dose, the maximum removal rate below $90 \%$, which has no promoting values.

\subsection{Formula Optimization Experiments}

According to the above composite flocculant on the removal rate of turbidity in the raw water, about $0.30 \mathrm{~mL}$ in CS, CF-PAC added amount is about $0.9 \mathrm{~mL}$ and Modified montmorillonite added amount is about $0.1 \mathrm{~mL}$, 
the turbidity removal rate as high as $98 \%$ above. According to the result of the analysis above, the flocculant formula was optimized in Figure 8 below.

\subsection{Comparisons of Improved Composite Flocculants and Traditional Flocculant PAC}

When compared with the working liquid PAC in Wuhan waterworks, its characteristics can be clearly seen. According to the data provided by the water quality detection center of Wuhan water group, flocculating agent price is $700 \mathrm{Yuan} / \mathrm{ton}$, the amount of $20 \mathrm{~kg}$ flocculating agent was treated in 1 ton raw water. The raw material cost, removal rate of SS, removal rate of $\mathrm{Al}^{3+}$ of the two flocculants were compared. Raw water turbidity is 71.8 NTU, aluminum ion concentration is $0.735 \mathrm{mg} \cdot \mathrm{L}^{-1}$. The experimental results are shown in Table 1 CS-Modified montmorillonite-CF-PAC did show a certain advantages, whether in the flocculation effect or chelate metal ions. And its cost is lower than the traditional, with a spread value.

\section{The Mechanism of Flocculation Analyses}

CS as linear long-chain structure of polymer, which its molecular chain distribution on free amino(- $\left.\mathrm{NH}^{2}\right)$ and hydroxyl(-OH) and these groups have lone pair electrons makes those groups presents alkalescency so that they can easy to combine the water protons $\left(\mathrm{H}^{+}\right)$to form a cation type electrolyte. Natural raw water contains clay, bacteria, etc make waters are electronegative colloid system, CS flocculants function in the wastewater by charge neutralization, adsorption bridging and bridging effect mechanism. The aluminum ions residue in water greatly reduces because of metal ion chelating of CS mainly used to remove metal ions contains null dorbitals.

After natural montmorillonite Sodium-modified and mixed with aluminum cross-linking agent, polymerized cross-linking agent was introduced and replaced exchangeable cations. So the mixing layer structure of montmorillonite changed into layer columnar and smaller two-dimensional molecular sieve type structure, bigger specific surface area, interlayer domain further open and the better absorption.

Modified aluminum chloride can make a more stable rearrangement structure on the surface of the colloidal solid after dissolution. It can act directly on the surface contaminants and show the strong electricity neutralization and bridging role. When the CF-PAC allowed combining with CS that strengthened positive charge on its surface and has a stronger affinity for contaminants which cany negative charge. The composite chemicals can efficiently remove pollutants in source water of Yangtze River by bridging with netted structure.

\section{Conclusion}

The composite flocculates' best formula $\mathrm{V}(0.1 \mathrm{wt} \%$ CF-PAC): V (0.01 wt \% CS): V (0.3 wt \% Modified montmorillonite) $=9: 3: 1$. The composite flocculants cost converting the industrial materials, in particular: treating per 1 ton raw waters with $0.05 \mathrm{wt} \%$ CF-PAC $4.5 \mathrm{~L}, 0.01$ $\mathrm{wt} \% \mathrm{CS} 1.5 \mathrm{~L}$ and modified montmorillonite $0.5 \mathrm{~L}$ respectively. Compared with traditional chemical flocculant (PAC), it increases the removal efficiency for SS by $0.62 \%$ and concentrations of $\mathrm{A}^{3+}$ ion by $70.65 \%$, and

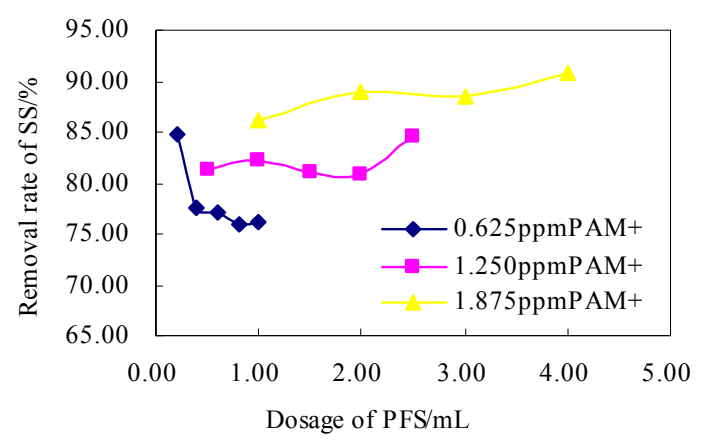

Figure 7. Flocculation effect of $\mathrm{PAM}^{+}$-PFS combination.

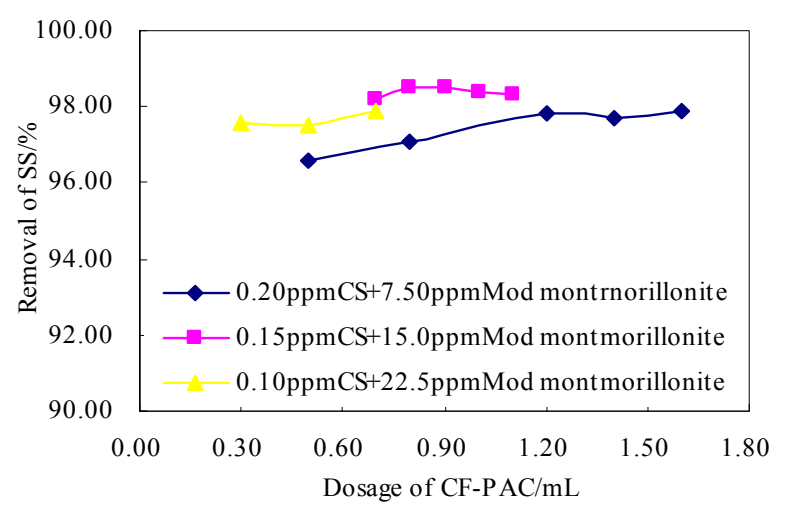

Figure 8. Flocculation effect of CS-Modified montmorillonite-CF-PAC combination.

Table 1. Comparison of main economic and technical indexes between two kinds of flocculants.

\begin{tabular}{|c|c|c|c|c|c|c|c|}
\hline Flocculant & $\begin{array}{c}\text { Cost of treating } 1 \text { kiloton } \\
\text { of wastewater/Yuan }\end{array}$ & $\begin{array}{l}\text { Decline rate } \\
\text { of cost } / \%\end{array}$ & SS/NTU & $\begin{array}{l}\text { Removal rate } \\
\text { of } S S / \%\end{array}$ & $\begin{array}{l}\text { Relative removal } \\
\text { rate of SS/\% }\end{array}$ & $\begin{array}{c}\text { Removal rate } \\
\text { of } \mathrm{Al}^{3+} / \%\end{array}$ & $\begin{array}{c}\text { Relative removal } \\
\text { rate of } \mathrm{Al}^{3+} / \%\end{array}$ \\
\hline $\begin{array}{l}\text { Traditional } \\
\text { flocculant }\end{array}$ & 14.3 & - & 1.57 & 97.81 & - & 22.53 & - \\
\hline $\begin{array}{l}\text { Composite } \\
\text { flocculant }\end{array}$ & 12.7 & 12.43 & 1.13 & 98.43 & 0.62 & 93.18 & 70.65 \\
\hline
\end{tabular}


decreases the cost of flocculants by $12.43 \%$. This composite flocculants agent cost is relatively low and good treatment effect and effluent discharge standard can be achieved. For "low aluminum" requirement of water quality has a strong competitive advantage to reduce the potential hazard to human health, it should be used widely in the field of water treatment.

\section{REFERENCES}

[1] A. Matilainen, M. Vepsäläinen and M. Sillanpää, "Natural Organic Matter Removal by Coagulation during Drinking Water Treatment: A Review," Advances in Colloid and Interface Science, Vol. 159, No. 2, 2010, pp. 189197. doi:10.1016/j.cis.2010.06.007

[2] V. K. Gupta and A. Imran, "Environmental Water: Advances in Treatment, Remediation and Recycling," Newnes, 2012.

[3] F. Spellman and J. E. Drinan, "The Drinking Water Handbook," CRC Press, 2012.

[4] M. Naushad and Z. A. AL-Othman, "Ion Exchange Materials and Environmental Remediation/Ion Exchange Technology II," Springer, Berlin, 2012.

[5] F. Renault, B. Sancey, P. M. Badot, et al., "Chitosan for Coagulation/Flocculation Processes-An Eco-Friendly Approach," European Polymer Journal, Vol. 45, No. 5, 2009 , pp. 1337-1348.

[6] K. M. Shareef, "Sorbents for Contaminants Uptake from Aqueous Solutions. Part I: Heavy Metals," World Journal of Agricultural Sciences, Vol. 5, No. S, 2009, pp. 819831.

[7] L. Cheng, Y. Z. Yu, Y. X. Zhou, et al., "The Research Progress of Flocculants in Sewage Sludge Dewatering," Advanced Materials Research, Vol. 610-613, 2013, pp. 1518- 1521.

[8] S. Li, "Application of Flocculants to Water Treatment and Its Forecast," Industrial Water Treatment, Vol. 30, No. 6, 2010, pp. 5-6.

[9] M. Fan, Q. Hu and K. Shen, "Preparation and Structure of Chitosan Soluble in Wide pH Range," Carbohydrate Polymers, Vol. 78, No. 1, 2009, pp. 66-71.

[10] S. V. Madihally and H. W. T. Matthew, "Porous Chitosan Scaffolds for Tissue Engineering," Biomaterials, Vol. 20, No. 12, 1999, pp. 1133-1142.

[11] X. Y. Shen, M. J. Lin and M. Song, "Photocatalyst $\mathrm{TiO}_{2}$ Supported on Bentonite for Water Organic Pollutants $\mathrm{Pu}$ rification: A Literature Review," Advanced Materials Research, Vol. 463, 2012, pp. 967-974.

[12] D. Teng, "From Chitin to Chitosan. Chitosan-Based Hydrogels: Functions and Applications," 2012. 